\title{
Determining soil organic carbon concentration in agricultural fields using a handheld spectroradiometer: Implication for soil fertility measurement
}

\author{
ElKamil Tola ${ }^{1 *}$, Khalid A. Al-Gaadi ${ }^{1,2}$, Rangaswamy Madugundu ${ }^{1}$, Ahmed G. Kayad ${ }^{2}$, \\ Ahmed A. Alameen ${ }^{1}$, Haroon F. Edrees ${ }^{1}$, Mohamed K. Edrris ${ }^{1}$ \\ (1. Precision Agriculture Research Chair, King Saud University, Riyadh 11451, Saudi Arabia; \\ 2. Department of Agricultural Engineering, College of Food and Agriculture Sciences, King Saud University, Riyadh 11451, Saudi Arabia)
}

\begin{abstract}
The soil organic carbon (SOC) plays a vital role in plant growth and development, and therefore is considered as one of the most important indicators of soil quality. This study was carried out in the central region of Saudi Arabia to explore the potential of spectroscopy in determining the SOC concentration in low-fertility soils. Spectral reflectance data were collected, under the controlled laboratory conditions on 39 air-dried $2.0 \mathrm{~mm}$ sieved soil samples, using a handheld spectroradiometer of a wavelength range between $350 \mathrm{~nm}$ and $2500 \mathrm{~nm}$ in the direct contact probe mode. The concentration of the SOC was determined using the Walkley and Black (W\&B) and the UV-VIS spectrophotometric methods. The increase in the concentration of SOC was associated with a decrease in the corresponding spectral reflectance. Regression analysis showed linear relationships with high significant correlation between the spectral reflectance and the SOC measured by both the UV-VIS (Model-1: $R^{2}=0.46, p=0.00015$ and $R M S E=6.6 \mathrm{~g} / \mathrm{kg}$ ) and the $\mathrm{W} \& \mathrm{~B}$ (Model-2: $R^{2}=0.48, p=8.92 \mathrm{E}-05$ and $R M S E=$ $2.8 \mathrm{~g} / \mathrm{kg}$ ) methods. For these models, two wavebands with wavelengths of $2167 \mathrm{~nm}$ (Model-1) and $1359 \mathrm{~nm}$ (Model-2) were identified as the most sensitive bands to the SOC concentration. The cross-validation confirmed the validity of Model-1 with $R^{2}, p$ and $R M S E$ values of $0.50,0.0099$ and $6.6 \mathrm{~g} / \mathrm{kg}$, respectively. The validation results of the Model- 2 showed values of $R^{2}$, $p$ and $R M S E$ of $0.72,0.00023$ and $4.0 \mathrm{~g} / \mathrm{kg}$, respectively. Results of this study revealed the possibility and the potential of using the spectral reflectance technique in predicting the concentration of SOC.
\end{abstract}

Keywords: soil fertility, organic carbon, modeling, spectroscopy, reflectance

DOI: $10.25165 /$ j.ijabe.20181106.4061

Citation: Tola E, Al-Gaadi K A, Madugundu R, Kayad A G, Alameen A A, Edrees H F, et al. Determining soil organic carbon concentration in agricultural fields using a handheld spectroradiometer: Implication for soil fertility measurement. Int $\mathrm{J}$ Agric \& Biol Eng, 2018; 11(6): 13-19.

\section{Introduction}

Soil organic carbon (SOC) refers to the carbon stored in the organic fraction of the soil, i.e. soil organic matter (SOM), excluding fresh and un-decomposed plant materials, such as straw and litter lying on the soil surface ${ }^{[1]}$. SOC is commonly expressed as the percentage of carbon weight to the total weight of dry soil. There are several direct and indirect methods available in the literature for the determination of the SOC. The amount of the SOM in the soil mainly depends on the soil condition, current and previous vegetation cover, topography, hydrological condition and farm management practices ${ }^{[2]}$. The SOC is considered as one of the most important soil components that plays a vital role in the plant growth and development processes, as a source of energy and

\section{Received date: 2017-12-19 Accepted date: 2018-05-06}

Biographies: Khalid A. Al-Gaadi, Professor, research interests: precision agriculture, farm machinery and agricultural technologies, Email: kgaadi@ksu.edu.sa; Rangaswamy Madugundu, Assistant Professor, research interests: GIS and remote sensing, Email: rmadugundu@ksu.edu.sa; Ahmed G. Kayad, Researcher, research interests: precision agriculture, Email: agala187@gmail.com; Ahmed A. Alameen, Researcher, research interests: precision agriculture, Email: aalameen@ksu.edu.sa; Haroon F. Edrees, Researcher, research interests: precision agriculture, Email: hfedrees@ksu.edu.sa; Mohamed K. Edrris, Researcher, research interests: precision agriculture, Email: medrris@ksu.edu.sa.

*Corresponding author: ElKamil Tola, Associate Professor, research interests: precision agriculture, farm power and machinery. P.O. Box 2460, Riyadh, 11451 Saudi Arabia. Tel: +966-11-4691904, Fax: +966-11-4678502, Email: etola@ksu.edu.sa. nutrients for soil microorganisms. Therefore, the SOC is viewed as the most important indicator of soil quality ${ }^{[3]}$. The importance of maintaining high levels of SOM or SOC is to improve the soil physical properties (e.g. reducing soil bulk density and soil compaction and increasing aggregate stability), conserve soil water, improve biological activities and increase the available nutrients, which all lead to a significant increase in the biomass and crop yield $^{[3]}$. Although the SOM is generally present in relatively small amounts (typical agricultural soils contain 1\%-6\% organic matter), it is the key to build and maintain healthy soil. Through its significant positive effect on most of the basic soil properties, every $1 \%$ increase in the SOM was observed to increase about $12 \%$ of the potential crop-yield ${ }^{[4]}$. In general, the SOM is the most important component of the agricultural soil and is considered as the key index of soil fertility.

Agricultural practices significantly contribute to the SOC loss through different mechanisms including deforestation, biomass burning, drainage, soil tillage, removal of crop residues, summer fallow and improper use of pesticides and other chemicals ${ }^{[5]}$. Therefore, estimation of the SOC concentration in agricultural soils at an acceptable level of accuracy is important, especially in the case when SOM exhibits strong spatial dependence and its measurement is time and labor-intensive procedure. Hence, there is an urgent need to develop rapid and inexpensive soil characterization techniques to support many important applications, such as precision agriculture ${ }^{[6]}$. Baharom et al. ${ }^{[7]}$ stated that information on spatial and temporal variations in soil 
characteristics is very important in precision agriculture applications to help farmers make sound farm management decisions.

Recent improvements in the use of spectrometry for fast and easy measurements and the significant progress in the analytical software programs have made this technology more attractive to researchers and scientists ${ }^{[6,8,9]}$. Soil spectral reflectance is a function of the soil constituents, such as organic materials, primary minerals, clay minerals and salts ${ }^{[6]}$. Compare to the conventional reference laboratory methods of SOC analysis, spectral reflectance measurements have been considered by many researchers as a rapid, non-destructive and cost-effective method for estimating the concentrations of organic carbon in agricultural soils ${ }^{[10-12]}$. Gholizadeh et al. ${ }^{[13]}$ stated that the analysis of soil spectral reflection in the visible-near infrared-short wave infrared (VIS-NIR-SWIR) range became a recognized method for the determination of a wide range of soil parameters, and is considered as a rapid, non-destructive and low-cost soil analytical method. The same conclusion was reported by Stevens et al. ${ }^{[14]}$, where the visible and near infrared spectroscopy was considered as an efficient alternative to the conventional SOC lab analysis methods, as it could improve the time and cost efficiency, provide accurate results and offer the possibility of monitoring small changes in SOC concentration.

Many studies have been conducted to investigate the characteristics of soil spectral reflection in regions of moderate to high soil fertility levels, but studies in low-fertility soils are still limited $^{[15]}$. Therefore, this study was carried out on the agricultural soil of the central region of Saudi Arabia of low soil fertility status characterized by the low organic matter content, low clay content and hyper-arid climatic condition ${ }^{[16]}$. The main goal of the study was to explore the potential of using spectroscopy in estimating SOC of agricultural soils. The specific objectives were: (i) investigate the correlation between the laboratory estimated SOC and the spectral reflectance output from a handheld spectroradiometer, and (ii) develop and cross-validate regression models for the identification of specific wavebands that were most sensitive to the SOC concentration in agricultural soils.

\section{Materials and methods}

\subsection{Study area}

The study was conducted at the Tawdeehia Arable Farm (TAF) located in the central region of Saudi Arabia between Al-Kharj and Haradh cities $\left(24^{\circ} 11^{\prime} 00^{\prime \prime} \mathrm{N}\right.$ and $\left.48^{\circ} 56^{\prime} 14.6^{\prime \prime} \mathrm{E}\right)$, as illustrated in Figure 1. The extension area of the farm, which comprised about 12 agricultural fields $\left(\approx 50 \mathrm{hm}^{2}\right.$ each) and irrigated through center pivot systems, was earmarked for modeling SOC content utilizing the reflectance measurements of the proximal fieldspec-3 spectroradiometer. The study area was under hyper-arid climate with a mean maximum temperature of $40.0^{\circ} \mathrm{C} \pm 2.0^{\circ} \mathrm{C}$ during summers and a mean minimum temperature of $15.0^{\circ} \mathrm{C} \pm 3.0^{\circ} \mathrm{C}$ during winters, and a mean air temperature of $35^{\circ} \mathrm{C}$. The study area was located within a very low precipitation region with a mean annual rainfall of about $90 \mathrm{~mm}$, most of which fell during the period from November to February. The soil in the study area was categorized as sand, loamy sand and sandy loam, and was characterized as a mild alkaline with a mean $\mathrm{pH}$ of 7.58 and a mean soil electrical conductivity (EC) of $2.36 \mathrm{dS} / \mathrm{m}$. The study area was flat with slight gradation ranging from $329 \mathrm{~m}$ to $453 \mathrm{~m}$ elevation. The main crops cultivated in the study farm included alfalfa, Rhodes grass, corn and carrot.

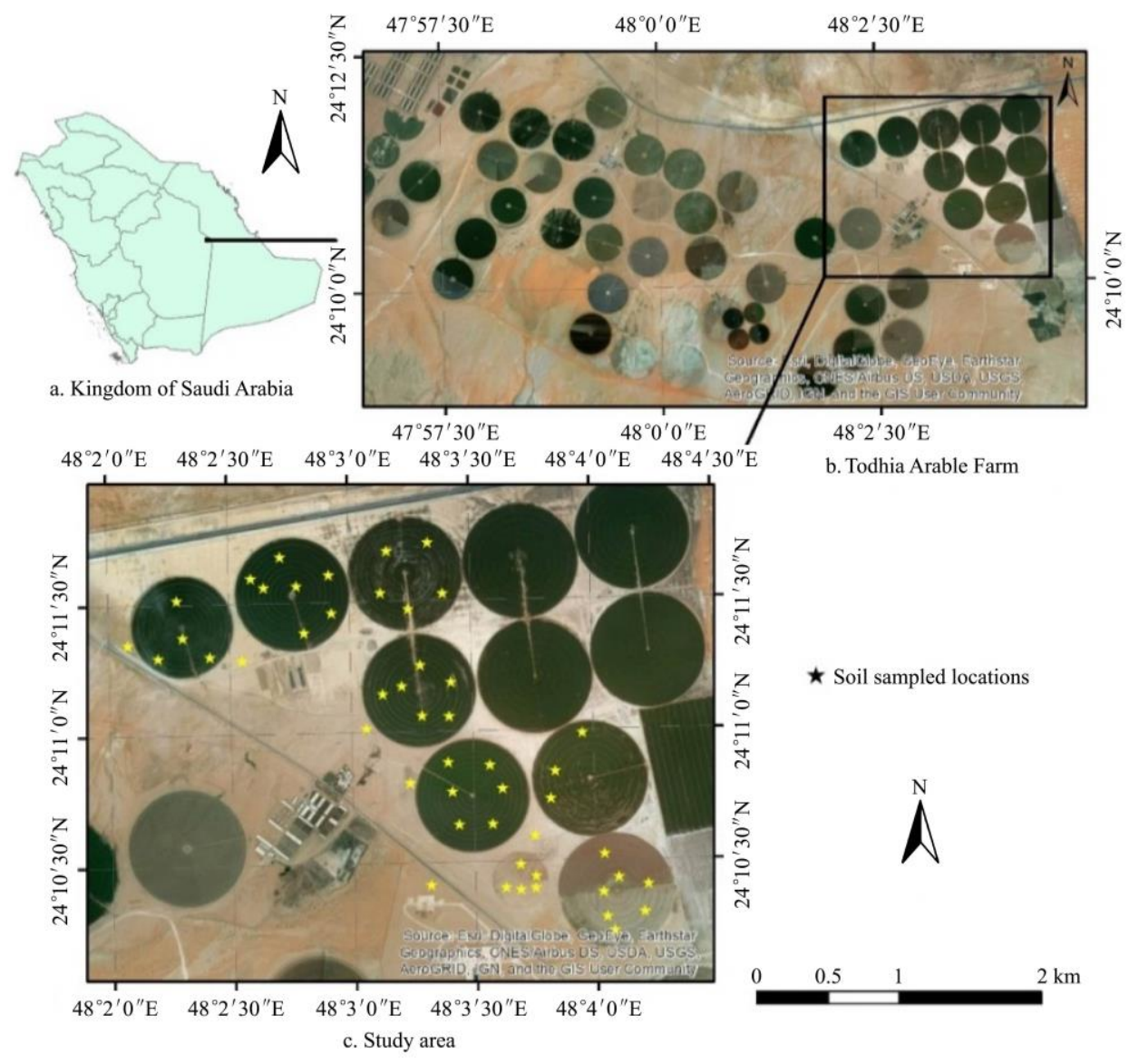

Figure 1 Experimental area and sampling locations 


\subsection{Field soil sample collection}

To collect soil samples from the study area, a detailed field survey was carried out and 39 composite soil samples were randomly collected (Figure 1) on March 13, 2016. Soil samples were collected with the assistance of a hand-held GPS receiver (Trimble GeoXH) for the identification of the pre-defined sample locations. A manual auger (SA6210C, with a bit diameter of $62 \mathrm{~mm}$ and a steel rod length of $1.0 \mathrm{~m}$ ) was used for the collection of the soil samples from the upper soil layer $(0$ to $10 \mathrm{~cm})$. The collected soil samples were characterized within three soil type categories, namely sandy soil (21 samples), loamy sand (2 samples) and sandy loam (16 samples) as shown in Table 1. The collected soil samples were analyzed in the laboratory for the surface SOC content.

Table 1 Characteristics of the analyzed soil samples

\begin{tabular}{ccccccc}
\hline $\begin{array}{c}\text { Number of } \\
\text { samples }\end{array}$ & \% Sand & \% Silt & \% Clay & Soil type & $\begin{array}{r}\text { Wilting } \\
\text { Point/\% }\end{array}$ & $\begin{array}{c}\text { Field } \\
\text { Capacity/\% }\end{array}$ \\
\hline 21 & 94.17 & 2.86 & 2.98 & Sand & 4.06 & 9.25 \\
2 & 85.00 & 5.00 & 10.00 & loamy Sand & 8.00 & 13.60 \\
16 & 76.09 & 10.31 & 13.59 & Sandy loam & 11.11 & 18.73 \\
\hline
\end{tabular}

\subsection{Soil organic carbon (SOC) analysis}

Two commonly used methods were selected for the determination of the SOC in this study, namely (a) Walkley and Black (W\&B) titration method ${ }^{[12,17]}$ and (b) UV-VIS spectrophotometric method ${ }^{[18-20]}$. For both methods, the organic matter was oxidized by chromic acid. In case of titration; however, there was a back titration of the unconsumed potassium dichromate against the ferrous sulphate or ferrous ammonium sulphate (redox titration). The carbon in the analyzed soil samples was oxidized as given in Equation (1):

$$
2 \mathrm{~K}_{2} \mathrm{Cr}_{2} \mathrm{O}_{7}+8 \mathrm{H}_{2} \mathrm{SO}_{4}=2 \mathrm{~K}_{2} \mathrm{SO}_{4}+2 \mathrm{Cr}_{2}\left(\mathrm{SO}_{4}\right)_{\mathrm{a}}+3 \mathrm{CO}_{2}+8 \mathrm{H}_{2} \mathrm{O}
$$

\subsubsection{Walkley and Black (W\&B) method}

The collected soil samples were air-dried and sieved $(<2 \mathrm{~mm})$ to remove plant debris and large root matter. $10 \mathrm{~mL} \mathrm{~K}_{2} \mathrm{Cr}_{2} \mathrm{O}_{7}$ $(0.167 \mathrm{M})$ and $20 \mathrm{ml} \mathrm{H}_{2} \mathrm{SO}_{4}(96 \%)$ were added to $1.0 \mathrm{~g}$ soil. After 30 minutes, the solution was diluted with $200 \mathrm{~mL}$ water. Furthermore, $10 \mathrm{~mL} 85 \% \mathrm{H}_{3} \mathrm{PO}_{4}$ and $0.2 \mathrm{~g} \mathrm{NaF}$ were added to the solution in order to complex the $\mathrm{Fe}^{3+}$, which was expected to interfere with the titration endpoint. Subsequently, $2.0 \mathrm{~mL}$ ferroin indicator were added and titrated with a $0.5 \mathrm{~N}$ ferrous ammonium sulphate (FAS) until the color flashed from yellowish green to greenish, and finally, the brownish red color appeared at the endpoint. Reagent blanks without soil were run for each set of six titrations following the above procedure. The concentrations of the oxidizable organic carbon were calculated from the difference between the titrant volume of the reagent blank and the titrant volume of the sample. For each sample, the test was repeated three times and then averaged out. The amount of the FAS consumption during the titration was used to determine the SOC as in Equation (2):

$$
\text { Organic Carbon }=N \times(B-S) \times 0.003 \times \frac{100}{\text { Wt. of soil }}
$$

where, $N$ is the normality of the standard FAS; $B$ and $S$ are the amounts of the FAS utilized during the titration for the blank and soil sample, respectively.

\subsubsection{UV-VIS spectrophotometer method}

For this method, the standard curve was initially prepared using sucrose $\mathrm{e}^{[20]}$. $\quad 1.0 \mathrm{~g}$ sucrose was added to a $1000 \mathrm{ml}$ distilled water and the solution was standardized. Subsequently, series of standard concentrations $(0,10,50,100,150,200,250,300,350$,
400, 450 and $500 \mathrm{ppm}$ ) were prepared form the sucrose solution. To each standard, $10 \mathrm{ml}$ potassium dichromate and $20 \mathrm{ml}$ concentrated $\mathrm{H}_{2} \mathrm{SO}_{4}$ were added and the mixture was allowed to cool down. The mixture was made up to $100 \mathrm{ml}$ using distilled water and the densities at $600 \mathrm{~nm}$ wavelength were observed. The observed reflectances at $600 \mathrm{~nm}$ were used to prepare the standard curve and to calculate the mean carbon \% in the unit optical density (i.e. the factor F). The collected soil samples were sieved $(<1 \mathrm{~mm})$ and weighed $(1.0 \mathrm{~g})$ for the analysis. $10 \mathrm{~mL} \quad \mathrm{~K}_{2} \mathrm{Cr}_{2} \mathrm{O}_{7}(0.167 \mathrm{M})$ and $20 \mathrm{ml} \mathrm{H}_{2} \mathrm{SO}_{4}(96 \%)$ were added to $1.0 \mathrm{~g}$ soil in a $100 \mathrm{~mL}$ standard flask. After 30 minutes, the mixture was diluted to $100 \mathrm{~mL}$ with distilled water and kept overnight. Three replicates were prepared for each soil sample. Reagent blanks (without soil) were prepared to verify the response of the tested soil samples. The solution in the $100 \mathrm{~mL}$ standard flask was filtered through an acid-free filter paper. The filtrate was measured for spectral reflectance at $660 \mathrm{~nm}$ wavelength using the UV-VIS spectrophotometer (Lambda-35, Perkin Elmer) and the organic carbon (\%) was determined using Equation (3):

$$
\text { Organic carbon }=\text { Optical density } \times F
$$

where, $F$ is the mean carbon $\%$ in the unit optical density.

\subsection{ASD data collection (lab-based)}

Soil spectral reflectance data was collected under the controlled laboratory conditions on air-dried $2.0 \mathrm{~mm}$ sieved samples using the FieldSpec $\AA 3$ spectroradiometer (PANalytical Inc., Boulder, Colorado, USA, formerly: Analytical Spectral Devices), with a wavelength range of $350 \mathrm{~nm}$ to $2500 \mathrm{~nm}$, in the direct contact probe mode. To avoid disturbance from surroundings, the Petri dish $(150 \mathrm{~mm}$ diameter $\times 20 \mathrm{~mm}$ height $)$ was covered with black velvet paper. The total organic carbon content of the studied samples ranged from $0.06 \%$ to $3.0 \%$ $(0.6 \mathrm{~g} / \mathrm{kg}$ to $30 \mathrm{~g} / \mathrm{kg})$. For measuring the spectral reflectance, each soil sample was placed in a black colored Petri dish and the soil surface was carefully flushed and leveled using a ruler. To improve the reliability and the accuracy of this study's results, three spectra were averaged out to produce a single spectral reflectance for each soil sample following Gholizadeh et al. ${ }^{[13]}$

\subsection{Linear regression analysis}

To statistically quantify the relationship between the spectral reflectance and the SOC content, a linear regression model was produced using the IBM SPSS Statistics (version 1.0.0.781-2017, IBM, New York, USA). Before embarking on the regression analysis process, the obtained dataset was randomly divided into two subsets of $60 \%$ and $40 \%$ of the total number of the collected observations. This step was achieved through the SPSS tool of a random selection of sample cases. The range of the SOC contents for each subset was inspected based on the normal distribution curve, to make sure that the two subsets were not radically different in this regard. Normal distribution problems were solved through the advanced option of the SPSS software program of manual selection and deselection of particular cases. The first subset (containing $60 \%$ of observations) was used to produce the regression model (i.e. calibration data), and the second subset (containing $40 \%$ of observations) was used to cross-validate the model (i.e. validation data). The standard stepwise regression analysis method, which is commonly used to identify the most sensitive wavebands to a certain chemical constituent, was used in this study ${ }^{[21-24]}$. The analysis of variance (ANOVA) statistics was used to test the strength of the developed models through the coefficient of determination $\left(R^{2}\right)$, the histograms of the residuals and the normal probability plots, Collinearity and Cook's distance 
and Centered Lever Value. Once the models which exhibited the most relationship between the concentration of the SOC and the spectral reflectance were identified, their accuracy was further assessed by the total root-mean-square error (RMSE) following Ting et al. ${ }^{[23]}$, as in Equation (4):

$$
R M S E=\sqrt{\frac{1}{n-k-1} \sum_{i=1}^{n}\left(Y_{i}-\hat{Y}_{i}\right)^{2}}
$$

where, $Y_{i}$ and $\hat{Y}$ represent the measured and predicted values, respectively; $n$ is the amount of soil samples, and $k$ is the amount of the selected wavebands.

\section{Results and discussion}

\subsection{Soil reflectance data}

The response of the spectral reflectance to the amount of soil organic carbon was clearly represented by Figure 2 for all the collected soil samples. The overall pattern of the spectral reflectance of all the 39 tested soil samples was similar (Figure 2). However, each soil sample exhibited its unique spectral signature. This was explained by the selected spectral curves of five samples covering the whole range of the SOC concentration (Figure 3). These results provided an indication of the clear variation in the spectral reflectance of the investigated soil samples.

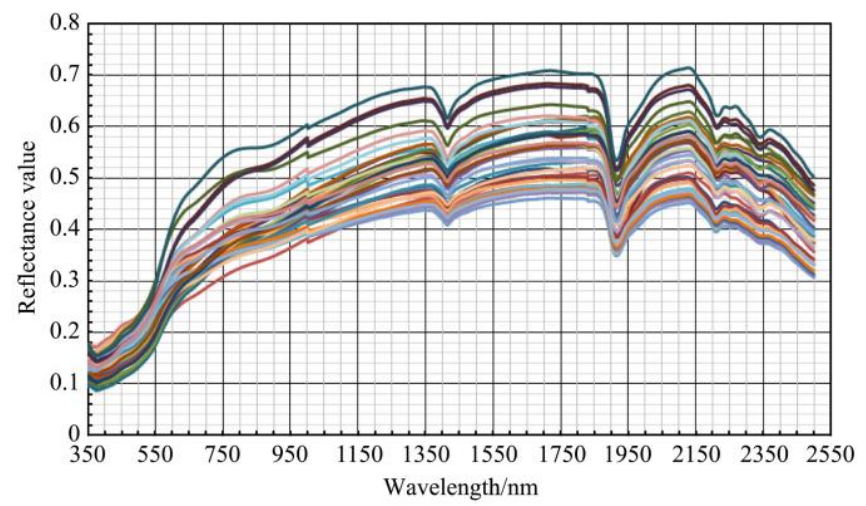

Figure 2 Spectral reflectance curves for all the 39 soil samples

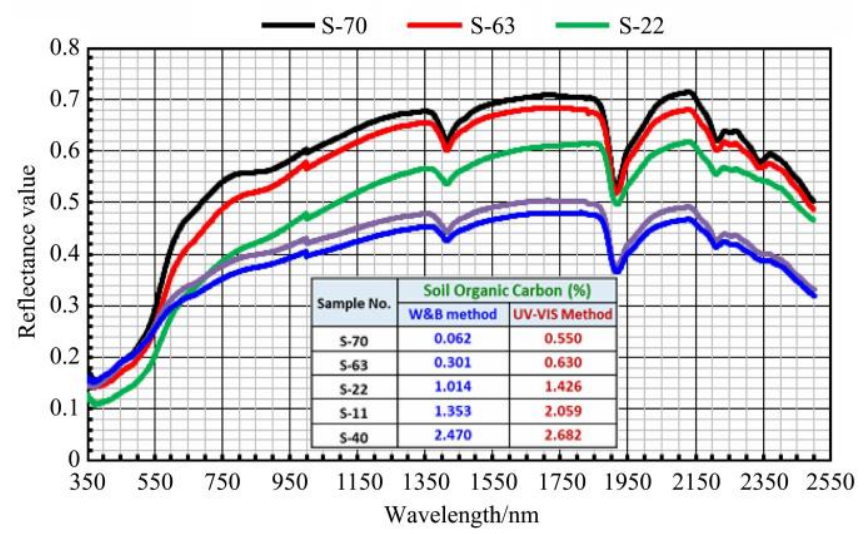

Figure 3 Spectral reflectance of five selected soil samples of different SOC concentration

As shown in Figures 3 and 4, the increase in the soil organic carbon content was associated with a significant decrease in the mean value of the spectral reflectance over the entire wavelength range $(350-2500 \mathrm{~nm})$ for the $S O C$ determined using both the W\&B $\left(R^{2}=0.46, \quad p=1.92 \mathrm{E}-06\right)$ and UV-VIS $\left(R^{2}=0.37, \quad p=4.53 \mathrm{E}-05\right)$ methods. This is in agreement with the results reported by Jiang et al. ${ }^{[11]}$, where lower SOC content leads to higher reflectance for almost the entire spectral range $(400-2350 \mathrm{~nm})$. This inverse relationship between the concentration of the SOC in the soil and the spectral reflectance is attributed to the fact that higher levels of organic material in the soil lead to darker soils, and therefore a lower reflectance ${ }^{[25]}$.

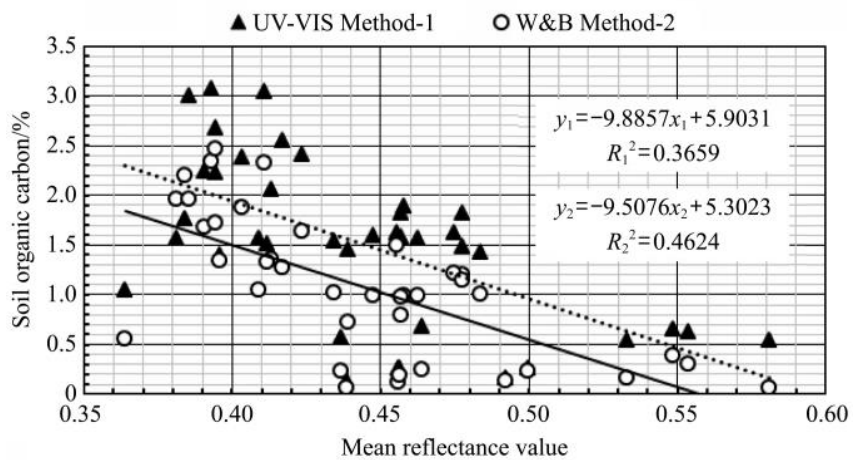

Figure 4 Mean SOC vs. the mean spectral reflectance

\subsection{Linear regression modeling}

To identify the most sensitive wavebands for the detection of SOC content in collected soil samples, the results of the SOC and the corresponding spectral reflectance data were subjected to a linear regression modeling performed using the IBM SPSS Statistics software program. Linear regression results (Table 2) showed two models with a significant correlation between the spectral reflectance and the SOC measured by the UV-VIS method, with $R^{2}$ values ranging between 0.46 and 0.69 . For these models, two wavebands with wavelengths of $1911 \mathrm{~nm}$ and $2167 \mathrm{~nm}$ were identified as the most sensitive bands to the concentration of the SOC. However, a single model, with a waveband of $1359 \mathrm{~nm}$ wavelength, exhibited a significant correlation between the spectral reflectance and the SOC estimated through the W\&B method. The ANOVA results (Table 3) also confirmed the significant relationship between the reflectance and the SOC content for the three models.

Table 2 Regression model summary

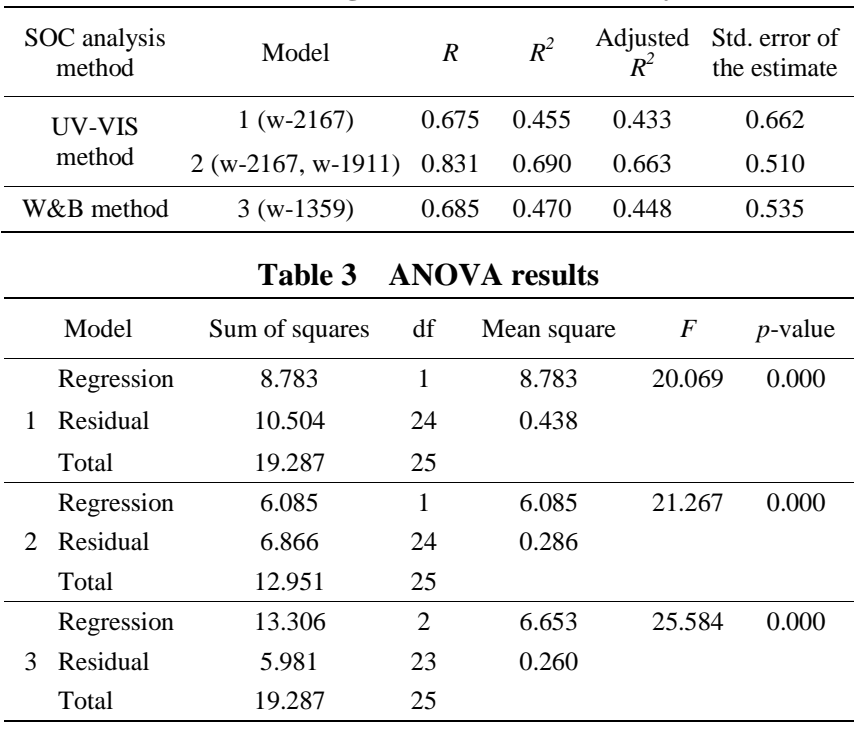

Based on the collinearity statistics including a Tolerance (T) value of 1.000 and a Variance Inflation Factor (VIF) of 1.000 (Table 4), Models 1 and 3 showed the most valid correlation between the reflectance and SOC for both the UV-VIS and W\&B methods, respectively. However, further investigations showed that both Models 1 and 2 exhibited some collinearity problems confirmed by the Eigenvalues of 0.006 and 0.060 and the Condition Index (CI) values of 18.285 and 18.982, respectively (Table 5). 
Table 4 Coefficients of model

\begin{tabular}{cccccc}
\hline \multirow{2}{*}{ Model } & \multicolumn{4}{c}{ Correlations } \\
\cline { 3 - 6 } & & Partial & Part & Tolerance & VIF \\
\hline 1 & w-2167 & -0.675 & -0.675 & 1.000 & 1.000 \\
\hline \multirow{2}{*}{2} & w-2167 & -0.746 & -0.624 & 0.051 & 19.773 \\
& w-1911 & 0.656 & 0.484 & 0.051 & 19.773 \\
\hline 3 & w-1359 & -0.685 & -0.685 & 1.000 & 1.000 \\
\hline
\end{tabular}

Table 5 Collinearity diagnostics

\begin{tabular}{|c|c|c|c|c|c|c|c|}
\hline \multirow{2}{*}{ Model } & \multirow{2}{*}{ Dimension } & \multirow{2}{*}{ Eigenvalue } & \multirow{2}{*}{$\begin{array}{l}\text { Condition } \\
\text { Index }\end{array}$} & \multicolumn{4}{|c|}{ Variance Proportions } \\
\hline & & & & (Constant) & $w-2167$ & w-1911 & w-1359 \\
\hline \multirow{2}{*}{1} & 1 & 1.994 & 1.000 & 0.00 & 0.00 & & \\
\hline & 2 & 0.006 & 18.285 & 1.00 & 1.00 & & \\
\hline \multirow{3}{*}{2} & 1 & 2.992 & 1.000 & 0.00 & 0.00 & 0.00 & \\
\hline & 2 & 0.008 & 19.169 & 0.97 & 0.01 & 0.01 & \\
\hline & 3 & 0.000 & 97.429 & 0.03 & 0.99 & 0.99 & \\
\hline \multirow{2}{*}{3} & 1 & 1.994 & 1.000 & 0.00 & & & 0.00 \\
\hline & 2 & 0.060 & 18.982 & 1.00 & & & 1.00 \\
\hline
\end{tabular}

Further exploration of the regression strength of the selected models was made through the histogram analysis, the normal probability plot and the residual analysis as shown in Figures 5 and 6 for the UV-VIS and W\&B methods, respectively. Results indicated that Models 1 and 2 represented the most valid models with a genuine relationship between the spectral reflectance and the SOC content at wavelengths of $2167 \mathrm{~nm}$ (Model-1, UV-VIS method) and $1359 \mathrm{~nm}$ (Model-2, W\&B method), with the prediction model given by Equations (5) and (6).

$$
\begin{aligned}
& \text { SOC \% }=-9.817 \times\left(\operatorname{Ref}_{2167 \mathrm{~nm}}\right)+6.793 \\
& \text { SOC \% }=-8.633 \times\left(\operatorname{Ref}_{1359 \mathrm{~nm}}\right)+6.793
\end{aligned}
$$

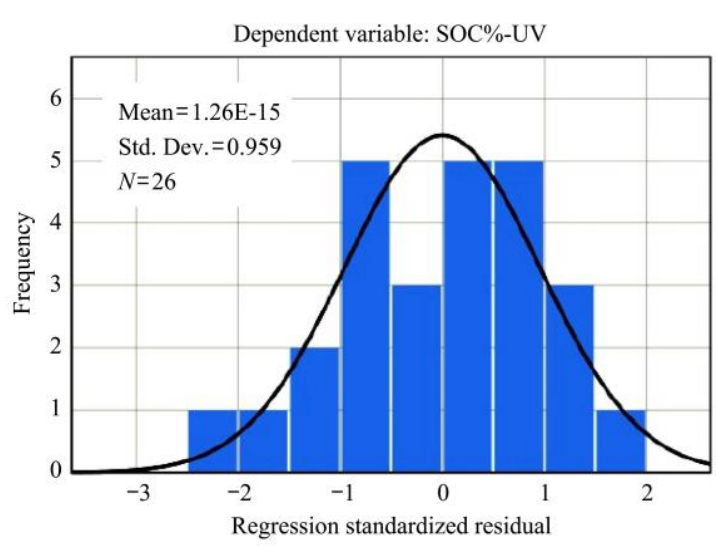

a. Histogram where, SOC is the soil organic carbon content; $\operatorname{Ref}_{2167 \mathrm{~nm}}$ and $\operatorname{Ref}_{1359 \mathrm{~nm}}$ represent the spectral reflectance at wavelengths of 2167 $\mathrm{nm}$ and $1359 \mathrm{~nm}$, respectively.

To investigate their accuracy in predicting the SOC, the two selected models, namely Model-1 (UV-VIS method) and Model-2 (W\&B method), were subjected to a cross-validation process using the samples that were not used in the generation of the models (40\% of the whole collected samples). For the SOC determined using the UV-VIS method, the cross-validation process confirmed the validity of the Model- 1 with an increase in the $R^{2}$ value from 0.46 (Figure 7a) to 0.50 (Figure $7 \mathrm{~b}$ ). The selected Model-1 exhibited a significant accuracy indicated by the correlation between the SOC determined by the UV-VIS method and the predicted SOC values, during both the calibration $\left(R^{2}=0.46\right.$, $p=0.00015)$ and the cross-validation $\left(R^{2}=0.50, p=0.0099\right)$ stages. The accuracy of the SOC prediction model- 1 was further confirmed by the RMSE value of $0.66 \%$ SOC concentration (equivalent to 6.6 $\mathrm{g} / \mathrm{kg}$ ) for the calibration stage. For the cross-validation stage, however, the RMSE value was also $0.66 \%$ SOC concentration (equivalent to $6.6 \mathrm{~g} / \mathrm{kg}$ ).

For the SOC determined using the W\&B method (Figure 8), the selected Model-2 showed a better accuracy during both the calibration $\left(R^{2}=0.48, \quad p=8.92 \mathrm{E}-05\right)$ and the cross-validation $\left(R^{2}=0.72, p=0.00023\right)$ processes. The high accuracy of this model was further confirmed by the RMSE value of $0.28 \%$ SOC concentration (which was equivalent to $2.8 \mathrm{~g} / \mathrm{kg}$ ) for the calibration stage. While for the cross-validation stage, the value of the RMSE was $0.40 \%$ SOC concentration (which was equivalent to $4.0 \mathrm{~g} / \mathrm{kg})$. The obtained values of the RMSE were within the reasonable accuracy level $(1.0 \mathrm{~g} / \mathrm{kg}$ to $15.0 \mathrm{~g} / \mathrm{kg})$ for the spectrally predicted $\mathrm{SOC}^{[14]}$.

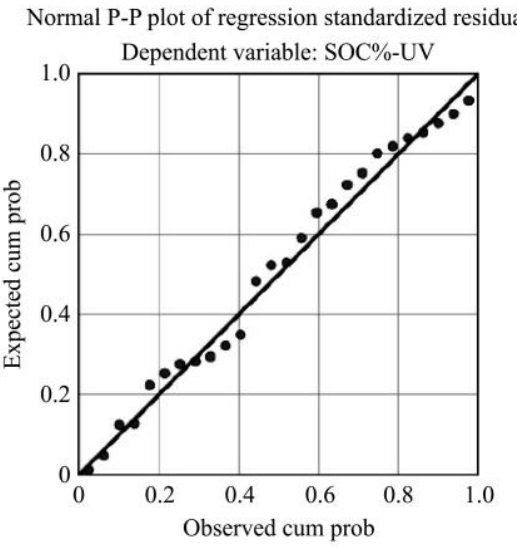

b. Cumulative probability

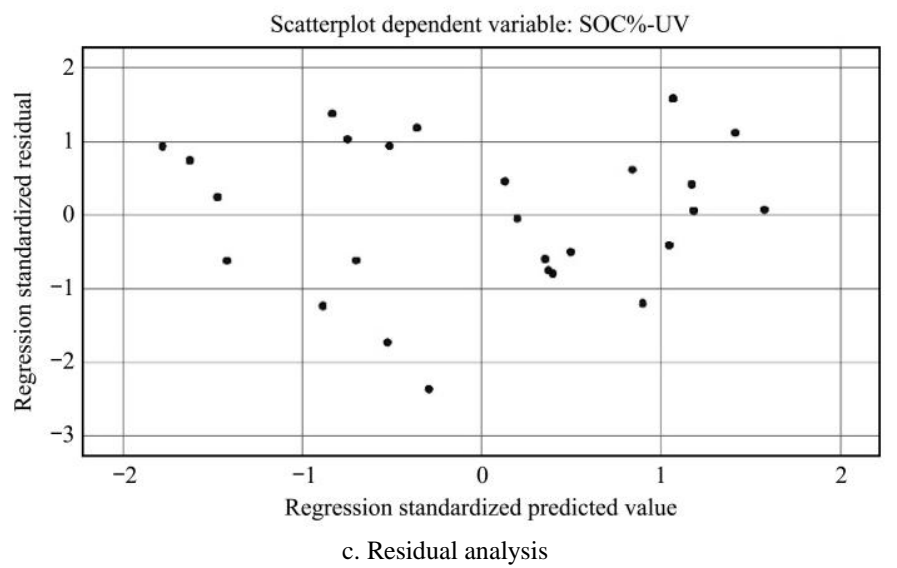

Figure 5 Histogram, cumulative probability and residual analysis for the UV-VIS method 


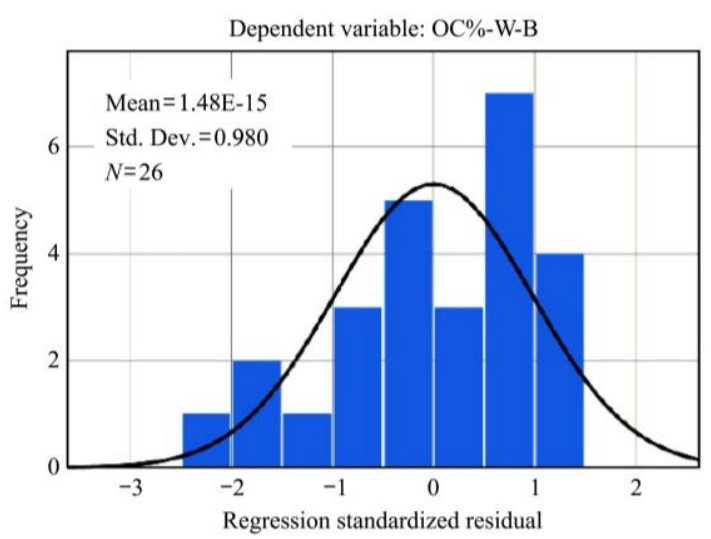

a. Histogram

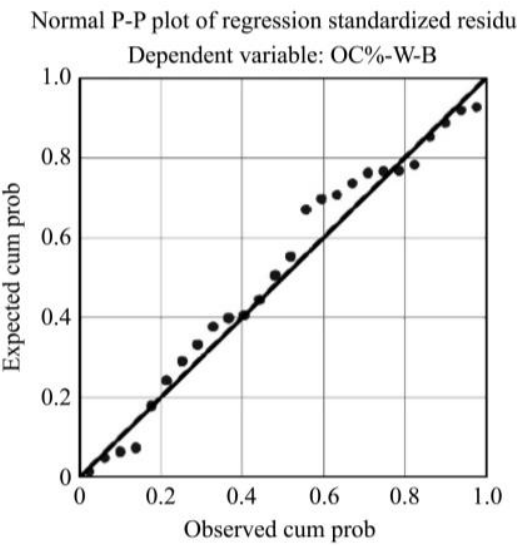

b. Cumulative probability

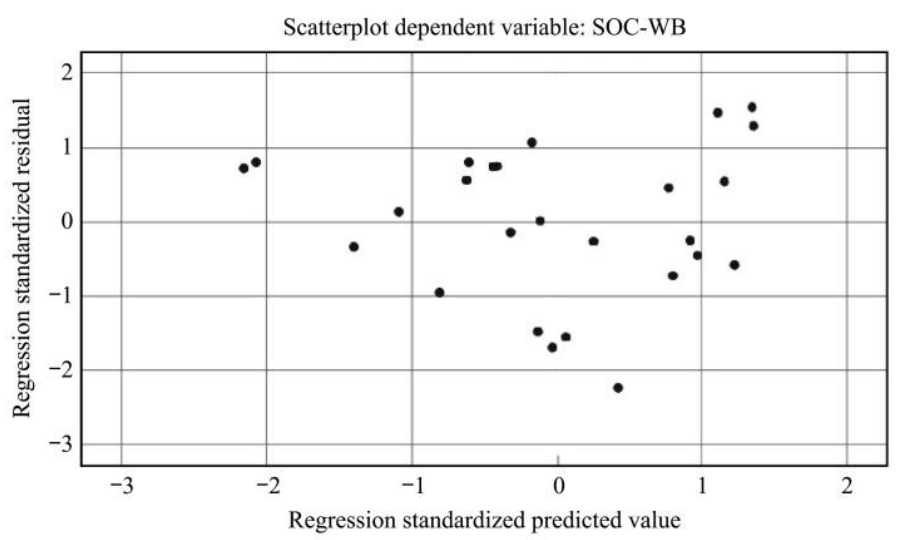

c. Residual analysis

Figure 6 Histogram, cumulative probability and residual analysis for the W\&B method

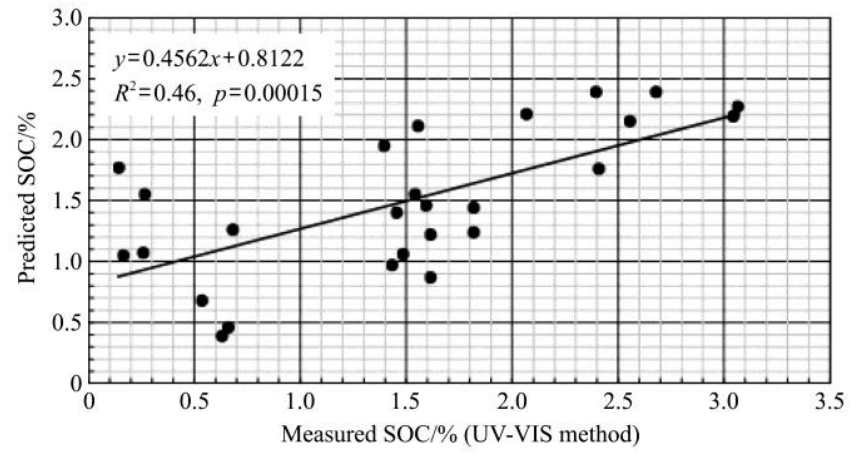

a. SOC prediction model

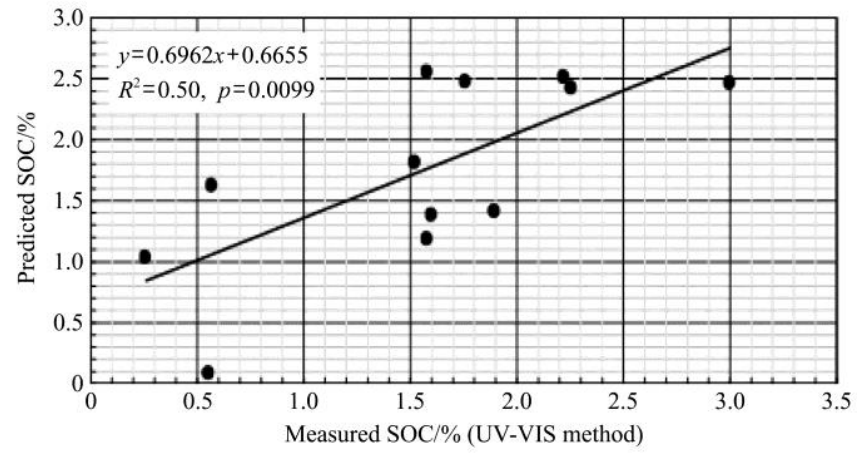

b. Model cross-validation

Figure 7 SOC prediction model and model cross-validation for the UV-VIS method

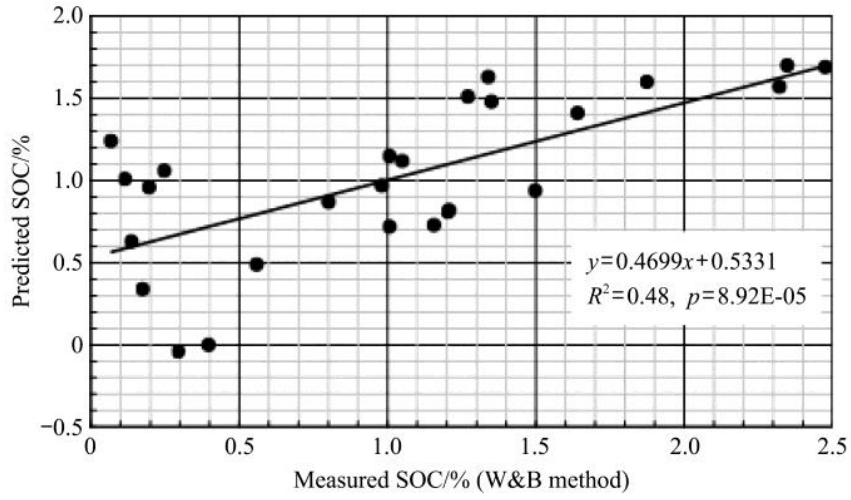

a. SOC prediction model

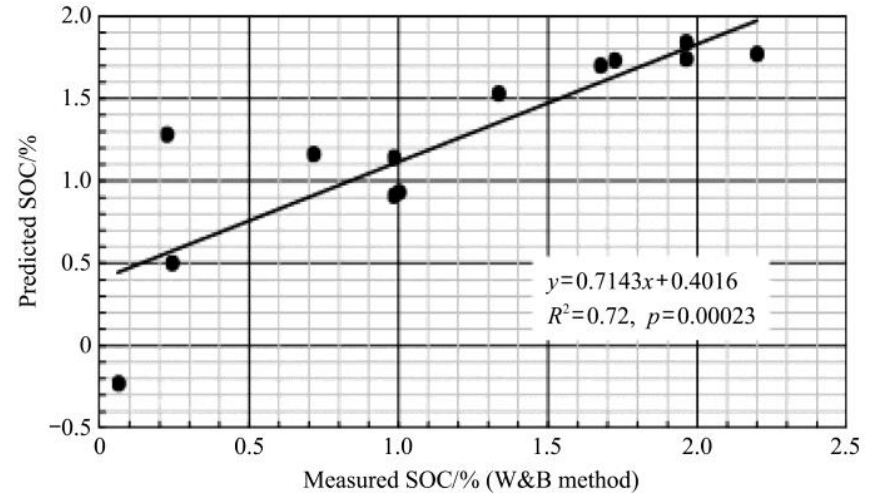

b. Model cross-validation

Figure 8 SOC prediction model and model cross-validation for the W\&B method

For the SOC determined using the W\&B method (Figure 8), the selected Model-2 showed a better accuracy during both the calibration $\left(R^{2}=0.48, \quad p=8.92 \mathrm{E}-05\right)$ and the cross-validation
$\left(R^{2}=0.72, p=0.00023\right)$ processes. The high accuracy of this model was further confirmed by the RMSE value of $0.28 \%$ SOC concentration (which was equivalent to $2.8 \mathrm{~g} / \mathrm{kg}$ ) for the calibration 
stage. While for the cross-validation stage, the value of the RMSE was $0.40 \%$ SOC concentration (which was equivalent to $4.0 \mathrm{~g} / \mathrm{kg}$ ). The obtained values of the RMSE were within the reasonable accuracy level $(1.0 \mathrm{~g} / \mathrm{kg}$ to $15.0 \mathrm{~g} / \mathrm{kg})$ for the spectrally predicted $\mathrm{SOC}^{[14]}$.

The results of model-2 (W\&B method) are in agreement with that of Daniel et al. ${ }^{[26]}$, which confirmed the capability of the spectral reflectance in predicting the concentration of SOM, with the best prediction bands of $520 \mathrm{~nm}, 960 \mathrm{~nm}$ and $1120 \mathrm{~nm}$ wavelengths. However, Ting et al. ${ }^{[23]}$ reported optimal models for predicting SOM content at wavebands of $849 \mathrm{~nm}, 1681 \mathrm{~nm}$ and $2187 \mathrm{~nm}$ wavelengths, which were in agreement with Model-1 and Model-2 of the current study.

\section{Conclusions}

In this study, a field study was carried out on a low fertility soil of the central region of Saudi Arabia, to explore the potential of using spectroscopy in estimating the soil organic carbon (SOC) concentration. The specific conclusions of this study are summarized as follows:

1) The concentration of the organic carbon in the soil was inversely proportional to the corresponding spectral reflectance over the entire wavelength range used in this study $(350-2500 \mathrm{~nm})$. Hence, the higher is the SOC content, the lower is the reflectance. The linear regression results showed two models with the most significant correlation between the spectral reflectance and the SOC measured by the UV-VIS (Model-1) and that measured by the W\&B method (Model-2). For these models, two wavebands with wavelengths of $2167 \mathrm{~nm}\left(R^{2}=0.46\right)$ for Model-1 and $1359 \mathrm{~nm}$ $\left(R^{2}=0.48\right)$ for Model-2 were identified as the most sensitive wavebands for the detection of organic carbon in the soil.

2) The SOC prediction model-1 exhibited a significant accuracy indicated by the $R^{2}, p$ and RMSE values of $0.46,0.00015$ and $6.6 \mathrm{~g} / \mathrm{kg}$, respectively. Model-2, however, showed a better SOC prediction accuracy with $R^{2}, p$ and RMSE values of 0.48 , $8.92 \mathrm{E}-05$ and $2.8 \mathrm{~g} / \mathrm{kg}$, respectively.

3) The cross-validation process confirmed the validity of the Model-1 with $R^{2}, p$ and $R M S E$ values of $0.50,0.0099$ and $6.6 \mathrm{~g} / \mathrm{kg}$, respectively. For Model-2, this process showed values of $R^{2}, p$ and $R M S E$ of $0.72,0.00023$ and $4.0 \mathrm{~g} / \mathrm{kg}$, respectively.

\section{Acknowledgements}

The authors are grateful to the Deanship of Scientific Research, King Saud University for funding this study through the Vice Deanship of Scientific Research Chairs. The unstinted cooperation and support extended by the staff of the Tawdeehiya farm in carrying out the field research work are gratefully acknowledged.

\section{[References]}

[1] Chan K Y, Oates A, Liu D L, Li G D, Pragnell R, Poile G,et al. A farmer's guide to increasing soil organic carbon under pastures. Industry \& Investment NSW, Wagga, Wagga, NSW. 2010. ISBN: 978174256010 6.

[2] Buringh P. Organic carbon in soils of the world. In: Woodwell G M (Ed.). The Role of Terrestrial Vegetation in the Global Carbon Cycle: Measurement by Remote Sensing; John Wiley \& Sons Ltd. 1984. pp. 91-109.

[3] Liu X, Herbert S J, Hashemi A M, Zhang X, Ding G. Effects of agricultural management on soil organic matter and carbon transformation - A review. ENVIRON., Plant Soil Environ., 2000; 52: 531-543.

[4] Magdoff F, van Es H. Organic matter: What it is and why it's so important. In: Building Soils for Better Crops: Sustainable soil management. Sustainable Agriculture Research and Education (SARE),
USDA, USA, 2009. pp. 9-21.

[5] Lal R. Soil carbon dynamics in cropland and rangeland. Environmental Pollution, 2002; 116: 353-362.

[6] Brown D J, Shepherd K D, Walsh M G, Mays M D, Reinsch T G. Globa soil characterization with VNIR diffuse reflectance spectroscopy. Geoderma, 2006; 132: 273-290.

[7] Baharom S N A, Shibusawa S, Kodaira M, Kanda R. Multiple-depth mapping of soil properties using a visible and near infrared real-time soil sensor for a paddy field. Engineering in Agriculture, Environment and Food, 2015; 8: 13-17.

[8] Van Maarschalkerweerd M, Husted S. Recent developments in fast spectroscopy for plant mineral analysis. Frontiers in Plant Science, 2015; 6: $1-14$.

[9] Aitkenhead M J, Gaskin G J, Lafouge N, Hawes C. Phylis: A low-cost portable visible range spectrometer for soil and plants. Sensors (Basel, Switzerland), 2017; 17(1): 1-14.

[10] Ingleby H R, Crowe T G. Reflectance models for predicting organic carbon in Saskatchewan soils. Canadian Agricultural Engineering, 2000; 42: 57-63.

[11] Jiang Q, Chen Y, Guo L, Fei T, Qi K. Estimating soil organic carbon of cropland soil at different levels of soil moisture using VIS-NIR spectroscopy. Remote Sens., 2016; 8: 1-16.

[12] Mouazen A M, Kuang B, de Baerdemaeker J, Ramon H. Comparison among principal component, partial least squares and back propagation neural network analyses for accuracy of measurement of selected soil properties with visible and near infrared spectroscopy. Geoderma, 2010; 158: 23-31.

[13] Gholizadeh A, Carmon N, Klement A, Ben-Dor E, Boruvka L. Agricultural soil spectral response and properties assessment: effects of measurement protocol and data mining technique. Remote Sens., 2017; 9 $1-14$.

[14] Stevens A, van Wesemael B, Bartholomeus H, Rossillon D, Tychon B, Ben-Dor E. Laboratory, field and airborne spectroscopy for monitoring organic carbon content in agricultural soils. Geoderma, 2008; 144: $395-404$.

[15] Summers D, Lewis M, Ostendorf B, Chittleborough D. Visible near-infrared reflectance spectroscopy as a predictive indicator of soil properties. Ecological Indicators, 2011; 11: 123-131.

[16] Sallam A Sh. Evaluation of some soils in Najd plateau (Central Region, Saudi Arabia. J. Saudi Soc. Agric. Sci., 2002; 1: 21-40.

[17] Combs S M, Nathan M V. Soil organic matter. In: North Central Regional Research Publication No. 221 (Revised) Recommended Chemical Soil Test Procedures for the North Central Region, 1998. pp. 53-58.

[18] Kiss K, Szalai Z, Jakab G, Madarász B, Zboray N. Characterization of soil organic substances by UV-Vis spectrophotometry in some soils of hungary. In: Hartemink A E, McSweeney K (Ed.). Soil Carbon. Progress in Soil Science. Springer International Publishing Switzerland, 2014. pp. 127-136.

[19] Peng X, Shi T, Song A, Chen Y, Gao W. Estimating soil organic carbon using VIS/NIR spectroscopy with SVMR and SPA methods. Remote Sens., 2014; 6: 2699-2717.

[20] Gupta I C, Yaduvanshi N P S, Gupta S K. Standard methods for analysis of soil-plant and water. Scientific publishers, India, 2012. 224.

[21] Wang C, Feng M, Yang W, Ding G, Xiao L, Li G, et al. Extraction of sensitive bands for monitoring the winter wheat (Triticum aestivum) growth status and yields based on the spectral reflectance. PLoS ONE, 2017; 12: 1-16.

[22] Ngo $\mathrm{T} \mathrm{H}$. The steps to follow in a multiple regression Analysis. Proceedings of the SAS Global Forum, 22-25 April, 2012, Orlando, Florida, USA, 2012.

[23] Ting H, Jing W, Li Z, Ye C. Spectral features of soil organic matter Geo-spatial Information Science, 2009; 12: 33-40.

[24] Stout F, Kalivas J H, Héberger K. Wavelength selection for multivariate calibration using tikhonov regularization. Applied Spectroscopy, 2007; 61: 85-95.

[25] Bartholomeus H M, Schaepman M E, Kooistra L, Stevens A, Hoogmoed W B, Spaargaren O S P. Spectral reflectance based indices for soil organic carbon quantification. Geoderma, 2008; 145: 28-36.

[26] Daniel K, Tripathi N K, Honda K, Apisit E. Analysis of spectral reflectance and absorption patterns of soil organic matter. The proceedings of the $22^{\text {nd }}$ Asian Conference on Remote Sensing, 5-9 November 2001, Singapore. 